\title{
Porous Activated Carbon Prepared from Highland Barley Straw by Phosphoric Acid Activation as a Conductive Agent for Improving Electrochemical Performance of $\mathrm{LiFePO}_{4}$ Cathodes
}

\author{
Wenliang Sun*, Rusi Hao \\ College of Chemical Engineering, Qinghai University, Xining 810016, China \\ *E-mail: sunwl3@ hotmail.com
}

doi: $10.20964 / 2021.04 .49$

Received: 20 November 2020 / Accepted: 23 January 2021 / Published: 28 February 2021

\begin{abstract}
Herein, porous activated carbon was synthesized from highland barley straw by phosphoric acid activation and used as a conductive agent for $\mathrm{LiFePO}_{4}$ cathodes. The morphology and microstructure are characterized by scanning electron microscopy and nitrogen adsorption and desorption. The results show that the porous activated carbon convenient three-dimensional porous microstructure. Compared with the conventional conductive agent carbon black Super P, the obtained porous activated carbon presents a high capacity of $153.63 \mathrm{~mA} \mathrm{~h} \mathrm{~g}^{-1}$ at $0.1 \mathrm{C}$, as well as an excellent rate performance and cycling stability. The simple method for the preparation of porous activated carbon as a conductive agent with an excellent electrochemical performance opens up a new opportunity of LiFePO4 cathodes for widespread applications in lithium-ion batteries.
\end{abstract}

Keywords: $\mathrm{LiFePO}_{4}$ cathode; Conductive agent; Biomass; Activated carbon; Highland barley straw

\section{$\underline{\text { FULL TEXT }}$}

(C) 2021 The Authors. Published by ESG (www.electrochemsci.org). This article is an open access article distributed under the terms and conditions of the Creative Commons Attribution license (http://creativecommons.org/licenses/by/4.0/). 